\title{
INTRODUÇÃO: \\ FICÇÃO E POLÍTICA, DA DITADURA CIVIL-MILITAR À CRISE DA DEMOCRACIA NO SÉCULO XXI
}

\author{
POR \\ Cristina Ferreira Pinto-Bailey \\ Washington and Lee University \\ REGINA ZILBERMAN \\ Universidade Federal do \\ Rio Grande do Sul
}

1.

Desde os primórdios da nação brasileira, e em especial desde a segunda metade do século XIX, a política, a sociedade e a história nacional continuamente dispuseram de lugar de relevância na nossa literatura, em particular na narrativa de ficção. Ao ocupar-se de contar uma história, o conto e o romance aproximam-se bastante de outras formas de relato, e não é difícil reconhecer a afinidade entre a narrativa de ficção e a historiografia, afinidade aliás basilar na obra de críticos como Antônio Cândido, Hayden White e Dominick LaCapra. ${ }^{1}$ A prosa de ficção é meia-irmã da narrativa historiográfica e, tal como a história, interessa-se pelo contexto sociopolítico em que as personagens trafegam. No entanto, a narrativa de ficção apresenta uma característica importante que a distingue da historiografia ou de outras formas de relato como o ensaio e o jornalismo: o tratamento estético dado à realidade que não é tão somente representada, mas também recriada.

A recriação estética da história presente e passada, aliada à "imaginação de uma possibilidade futura" (Machado, "Palavras" 37), convida o público leitor à reflexão crítica, fazendo da literatura poderoso instrumento político. Não por ser panfletária ou didática, nem por representar "a verdade", mas simplesmente porque nos leva pelas "fronteiras ambíguas entre o verdadeiro e o falso" (Machado, Infâmia 174), abrindo assim espaço à indagação e ao questionamento da realidade. Seja em tempos de censura explícita imposta por governos ditatoriais, seja em tempos de regressão política como o atual, quando presenciamos a manipulação dos fatos pela mídia e pelo estado, a

\footnotetext{
Ver, por exemplo, Literatura e sociedade (1965) e A educação pela noite (1987) de Cândido; Metahistory: The Historical Imagination (1973) e The Content of the Form (1987) de White; e History, Politics, and the Novel (1987) e History, Literature, Critical Theory (2013) de LaCapra, entre muitos outros estudos destes três autores.
} 
literatura oferece-nos "a mental armory" (Snyder 62)-armas para o pensamento crítico que nos preparam para o questionamento da realidade e para a resistência política-. É este o papel político que a literatura de ficção tem preenchido no Brasil.

Este número especial da Revista Iberoamericana toma como marco cronológico as últimas cinco décadas e como ponto de partida 1967, ou seja, três anos depois do golpe de estado de $1^{\circ}$ de abril de 1964 que instaurou a ditadura civil-militar no Brasil, e data de publicação da primeira edição do romance Quarup, deAntônio Callado (1917-1997).

Callado foi um dos mais importantes nomes da narrativa brasileira a partir da década de 1960, embora sua estreia como romancista tenha ocorrido em 1954 com Assunção de Salviano. Jornalista, dramaturgo, ensaísta e ficcionista, Callado foi uma das vozes mais críticas e criativas da narrativa de ficção brasileira a levantar-se contra a ditadura, especialmente com Quarup-romance monumental, romance-monumento-e as obras que a ele se seguiram: Bar Don Juan (1971), Reflexos do baile (1976) e Sempreviva (1981). ${ }^{2}$ Na década de 1980, quando a sociedade brasileira começava a retomar as vias democráticas, Callado publicou ainda os romances A Expedição Montaigne (1982), Concerto carioca (1985) e Memórias de Aldenham House (1989), além de vários outros livros, que incluem reportagem, teatro e contos.

Depois do golpe de 1964, e principalmente nos últimos anos daquela década e nas seguintes, Callado e outros escritores brasileiros buscaram retratar e denunciar a situação de exceção em que se encontrava o país. A literatura desempenhou então importantíssimo papel, em uma época em que a censura impediu o jornalismo de cumprir sua função de informar, e perseguiu violentamente outras manifestações artísticas cujas formas de expressão permitiam a comunicação mais direta e imediata de denúncia e resistência políticas, tais como o teatro e a música popular.

Isso não significa que a literatura de ficção também não tenha sofrido censura. De fato, ficcionistas como Ignácio de Loyola Brandão, Renato Tapajós e Rubem Fonseca, assim como poetas e autores de romances-reportagem-como José Louzeiro, autor de Aracelli, meu amor (1976)-viram seus livros impedidos de circular. Entretanto, ainda assim a linguagem estética da prosa de ficção-com o uso da polifonia, fragmentação, simbolismo, alegoria-abriu canais de comunicação com o público leitor que muitas vezes escaparam ao crivo dos censores. ${ }^{3}$ Nesse sentido, vale lembrar Reflexos do baile, de Callado, uma narrativa polifônica composta de fragmentos de cartas, bilhetes, memorandos e diários, escritos em linguagem enigmática e cujos autores e destinatários nunca são claramente identificados, cabendo aos leitores o trabalho de

2 Caracterizamos Quarup como romance-monumento no sentido de ser ele "local da memória", arquivo em prosa de ficção a preservar momentos da história nacional que permitem repensar a identidade coletiva da nação. Ver John R. Gillis, "Memory and Identity: The History of a Relationship".

3 Sobre a censura durante a ditadura militar, ver Sandra Reimão, "'Proíbo a publicação e circulação...' -censura a livros na ditadura militar".

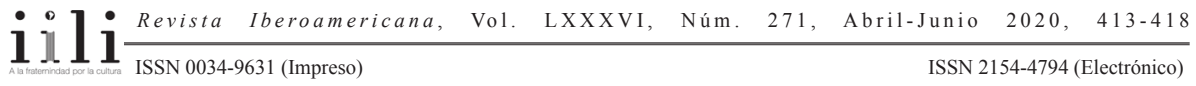


montar o significado textual como um quebra-cabeças, à medida em que mergulham na realidade que o romance de Callado recria.

É impossível exagerar o impacto que 25 anos de ditadura civil-militar tiveram sobre a sociedade brasileira. Por sua vez, a literatura produzida entre o final da década de 1960 e os anos 1980 foi visivelmente marcada pelo processo político desde o golpe de 1964, e com frequência refletiu-temática e formalmente-a situação de extrema exceção do período. As obras daquelas décadas permaneceram atuais, servindo como registro, denúncia e testemunho de eventos muitas vezes ocultados aos olhos do público. Elas representam, nas palavras de Regina Dalcastagnè, um “espaço da dor, transformam-se em cicatrizes profundas, visíveis-marcas de um tempo que não admite ser esquecido" (141).

Por outro lado, também na ficção brasileira do século XXI, tem se observado renovado interesse por aquele período da história nacional. Em romances como Azul corvo de Adriana Lisboa, Um homem é muito pouco de Ronaldo Costa Fernandes, ou ainda $O$ punho e a renda de Edgar Telles Ribeiro-todos publicados em 2010-, nossa narrativa de ficção hoje continua a examinar os traumas, cicatrizes e conflitos que permaneceram irresolutos, assim como a retratar o sentimento de orfandade que a ditadura civil-militar legou à sociedade brasileira. Em todo esse longo intervalo, do final dos anos sessenta aos dias de hoje, a literatura-e em especial a narrativa de ficção-quer esmiuçar o passado, "relembrar, desenterrar os fatos que ameaçam ficar sepultados nas senzalas de nós mesmos", como afirma Lígia Chiappini M. Leite sobre Sempreviva de Callado (178).

Ao mesmo tempo, a ficção brasileira contemporânea continua o exame crítico dos desafios sociais e políticos que o país tem enfrentado nas primeiras décadas do século XXI, quando o processo de redemocratização da sociedade brasileira rapidamente cedeu lugar à crise das instituições democráticas, com o impeachment irregular da presidente Dilma Rousseff em 2016, um Congresso Nacional majoritariamente envolvido em escândalos de corrupção, e o desmantelamento dos avanços sociais alcançados nos governos anteriores pelo governo "de transição" de Michel Temer. Todo esse retrocesso político vai culminar na eleição para presidente, em outubro de 2018 , do candidato de extrema direita Jair Bolsonaro.

O propósito deste número especial da Revista Iberoamericana é, assim, reunir ensaios que exploram as muitas vertentes da ficção política brasileira dos últimos cinquenta anos. Alguns deles oferecem novas perspectivas sobre a obra de importantes escritores que escreveram durante a ditadura e na primeira década que se seguiu à abertura política iniciada com a Lei da Anistia de 1979, tais como Érico Veríssimo, Lygia Fagundes Telles, Ana Maria Machado, e o próprio Callado. Por outro lado, outros dos ensaios aqui coligidos examinam obras de uma "segunda geração da ditadura militar”, tal como apontam Claudio Maíz e Claudia Lorena Fonseca no título de seu 
ensaio, incluindo romances de autores nascidos nas décadas de 1960 e 1970, como Fernando Bonassi (n. 1962), André Sant'Anna (n. 1964), Adriana Lisboa (n. 1970) e Tatiana Salem Levy (n. 1979). Nestas obras, ao trabalho da memória concorrem as pós-memórias que aqueles que vivenciaram os anos de autoritarismo deixaram para as gerações mais jovens, memórias pessoais, familiares ou coletivas das experiências traumáticas da ditadura brasileira.

2.

Destaquemos o arco temporal escolhido, que se estende por cinquenta anos. Essas cinco décadas podem ser divididas em duas metades, equivalendo a primeira à fase do regime militar, e a segunda, ao período de redemocratização, que avançou por um prazo, mas que sofreu inquestionável retrocesso a partir de 2016, seja pelo modo como se deu a mudança na presidência do país, seja pelas aspirações, expostas em manifestações não tão tímidas como se desejaria, de nostalgia e desejo de retorno ao passado em que, sob a égide do Exército, mas com a consciente adesão de segmentos civis conservadores da sociedade brasileira, o Estado de Direito foi atropelado por leis de exceção.

E não só o Brasil foi submetido à repressão, pois, no decorrer aqueles 25 anos, submergiram outras democracias na América Latina: Argentina, Bolívia, Chile, Peru e Uruguai representam esse grupo, se quisermos nos ater a países fronteiriços. O legado cultural pode, assim, mostrar-se transnacional, ainda que as afinidades derivem de contextos mediados pela dor, o sofrimento e o medo. Explica-se, portanto, porque o tema da repressão e da personagem traumatizada pelos seus efeitos migre para a arte. E não surpreende que ele repercuta não só na cultura "elevada", representada aqui pela literatura, mas também na cultura de massas, que o expressa por meio do cinema, histórias em quadrinhos, canções, blogues, vídeos.

Ao assim proceder, a cultura revela-se um lugar de resistência, com efeitos que extravasam para além do campo artístico e intelectual. Pois, quanto mais veículos irmanarem-se na denúncia, tanto mais se evidenciarão condições para que os fatos delatados não sejam esquecidos. Até poderão se repetir ou agudizar, porque a cultura não tem meios de impedi-los; mas estarão disponíveis as oportunidades de identificá-los e reconhecê-los com mais propriedade, pois, provavelmente pela primeira vez em sua história e com notável intensidade, uma cultura de explícito tema político tem lugar predominante entre as expressões artísticas, em seus diferentes gêneros.

A questão política na literatura de ficção é bastante relevante, porque apresenta ramificações que não conhecem limites geográficos. A crise da democracia que o Brasil vive hoje não é de todo distinta da situação por que atravessam muitos outros países pelo mundo afora. As semelhanças, porém, são mais profundas entre o Brasil e seus vizinhos hispano-americanos, e a proximidade dessas experiências é ainda mais inquestionável no que diz respeito à ditadura brasileira instaurada em 1964, a

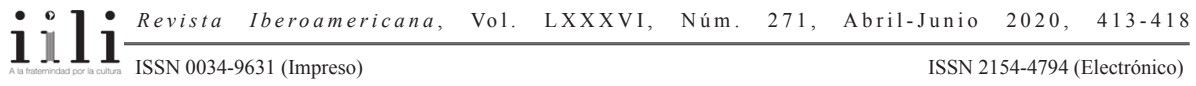


primeira de uma série de tiranias de direita instituídas no Cone Sul, na segunda metade do século XX, apoiadas pelo governo estadounidense e construídas sobre uma rede de cooperação entre elementos dos vários governos ditatoriais. Como afirma Márcio Seligmann-Silva, é "impossível tratar desse tema da memória pós-ditatorial no Brasil sem falar de seus vizinhos" (14).

Assim, além de ensaios que enfocam exclusivamente a ficção brasileira, incluemse aqui também artigos que examinam comparativamente obras e autores brasileiros e hispano-americanos, especificamente argentinos, o que vem ressaltar as conexões históricas e políticas entre os dois parceiros geográficos sul-americanos.

Mapear esse território é ainda uma tarefa por prosseguir e progredir. Com esse volume da Revista Iberoamericana, espera-se ter colaborado para dar ensejo a uma cartografia que é, também, proposta de reescrita da história, incluída nessa a literatura enquanto militância por um mundo mais justo.

\section{OBRAS CITADAS}

Cândido, Antônio. A educação pela noite e outros ensaios. 1987. São Paulo: Ática, 1989. Literatura e sociedade: estudos de teoria e história literária. 1965. São Paulo: Cia. Editora Nacional, 1985.

Dalcastagnè, Regina. O espaço da dor. O Regime de 64 no romance brasileiro. Brasília: Editora da UnB, 1996.

Gillis, John R., ed. Introduction. "Memory and Identity: The History of a Relationship". Commemorations: The Politics of National Identity. Princeton: Princeton UP, 1994. 3-23.

LaCapra, Dominick. History, Literature, Critical Theory. Ithaca: Cornell UP, 2013. History, Politics, and the Novel. Ithaca: Cornell UP, 1987.

Leite, Lígia Chiappini M. "Quando a pátria viaja: uma leitura dos romances de Antônio Callado". O nacional e o popular na cultura brasileira. Artes plásticas. Literatura. Carlos Zilio, João Luiz Lafetá e Lígia Chiappini M. Leite, eds. São Paulo: Brasiliense, 1983. 129-234.

Machado, Ana Maria. Infâmia. Rio de Janeiro: Objetiva, 2011.

"Palavras e saúde". Balaio: livros e leituras. Rio de Janeiro: Nova Fronteira, 2007. 30-43.

Reimão, Sandra. “'Proíbo a publicação e circulação...'-censura a livros na ditadura militar". Estudos avançados 28/80 (2014): 75-90.

Seligmann-Silva, Márcio. "Imagens precárias: inscrições tênues de violência ditatorial no Brasil". Roberto Vecchi e Regina Dalcastagnè, orgs. Estudos de Literatura Brasileira Contemporânea 43 (2014): 13-34.

Snyder, Timothy. On Tyranny: Twenty Lessons from the Twentieth Century. New York: Tim Duggan Books, 2017.

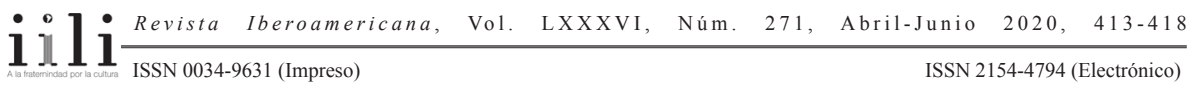


White, Hayden. The Content of the Form: Narrative Discourse and Historical Representation. Baltimore: Johns Hopkins UP, 1987.

Metahistory: The Historical Imagination in Nineteenth-Century Europe. 1973. Baltimore: Johns Hopkins UP, 2014. 